\title{
45. PETRORHAGIA SAXIFRAGA, UNA NUEVA ESPECIE PARA LA FLORA DE ANDALUCÍA OCCIDENTAL
}

\author{
M. Eugenia OCAÑA y M.A. MARTÍN MOSQUERO
}

Petrorhagia saxifraga, a new specie in west Andalusia Flora.

Palabras clave. Caryophyllacea, Petrorhagia, Andalucía Occidental.

Key words. Caryophyllacea, Petrorhagia, West Andalusia.

Petrorhagia saxifraga, perteneciente a la sect. Petrorhagia, es una especie de pastizales y hábitats saxícolas que se caracteriza, fundamentalmente, por su cáracter perenne, sus flores solitarias y terminales, y por sus brácteas de casi la mitad de la longitud del cáliz. Se distribuye por el C y S de Europa y SW de Asia, estando naturalizada en Suecia, Gran Bretaña y Norteamérica (Rabeler, 1985). En la Península Ibérica, representada por la var. saxifraga, se localiza en la cuenca baja del Duero y en las provincias de Valencia y Málaga (Romo, 1990).

Recientemente se ha localizado una población en Sevilla, Coripe, en el Peñón de Zaframagón, en ambos márgenes del río Guadalporcum (12-IV-1996, M.A. Martín
Mosquero y M.A. Ocaña SEV 138901) y constituye una novedad para la flora de Andalucía Occidental.

\section{BIBLIOGRAFÍA}

RABELER, R.K. -1985- Petrorhagia (Caryophylaceae) of North America. Sida, 11: 6-44.

ROMO, A.M. - 1990- Petrorhagia, en S. Castroviejo et al. (eds.): Flora Ibérica, II: 420-426.

Aceptado para su publicación en Junio de 1996

Dirección de los autores.Departamento de Biología Vegetal y Ecología. Facultad de Biología. Apdo. 1095. 41080, Sevilla. 